NOTA

$269-281$

\title{
LENGUAJE DE CONTRASTES SUTILES: EL SENTIDO HERMENÉUTICO DE LAS CIENCIAS HUMANAS SEGÚN CHARLES TAYLOR
}

The language of subtle contrasts: The hermeneutic sense of the social sciences according to Charles Taylor

Solange Cárcamo Landero*

\section{INTRODUCCIÓN}

En la perspectiva de unas ciencias humanas de carácter intercultural-crítico, la interpretación de la diversidad cultural supone el desarrollo de un lenguaje que nos permita expresar/articular el mundo de los otros, atendiendo a las distintas significaciones propias y ajenas que entran en juego en una situación específica. En este sentido, Taylor (2005) propone la noción de un "lenguaje de contrastes sutiles", como una manera de aproximar el lenguaje de las ciencias humanas al desarrollo de procesos de comprensión no etnocentristas que permitan esclarecer el carácter situado del conocimiento. Para entender el sentido profundo del carácter "sutil" de esta propuesta, podemos acudir a la tradición hermenéutica medieval que concebía la sutileza como el "método" que permitía "encontrar siempre una posibilidad, en donde los otros no la veían" (Beuchot, 20). Desde este punto de vista, un lenguaje de contrastes sutiles hace referencia a la posibilidad de articular un tercer lenguaje allí donde habitualmente solo podemos ver dos, que en principio resultan incomparables. Taylor (2005) lleva la sutileza hermenéutica al problema del diálogo entre culturas; tratando de evitar tanto el dogmatismo como el relativismo al momento de interpretar la otredad histórico-cultural. Para ello - nos dice - es necesario comprender que "el lenguaje de la ciencia neutral" debe ser superado por un "lenguaje científico esclarecedor" que "evita proyecciones etnocentristas" al reconocer que necesita "entender el lenguaje de la autocomprensión del otro pueblo", pues "la otra sociedad puede ser incomprensible en nuestros términos, o sea, en términos de nuestra autocomprensión" (Taylor, La libertad, 212-213).

Estas aseveraciones sobre el lenguaje de la ciencia nos hablan de una perspectiva hermenéutico-antropológica, cuyo sentido práctico se orienta a comprender al ser humano como agente capaz de actuar expresivamente desde un contexto culturalcomunitario que, a su vez, es narrativo y dialógico. A partir de ellas, podemos establecer una relación entre la búsqueda tayloriana de un lenguaje de contrastes sutiles y el proyecto ético-político configurado por la interculturalidad crítica ${ }^{1}$. Para el propósito de

\footnotetext{
${ }^{1}$ El carácter crítico de la interculturalidad hace referencia a la necesidad de cuestionar las condiciones del diálogo y visibilizar las causas reales del no diálogo entre las distintas culturas (Tubino, 2004). Así, se cuestionan los factores que condicionan actualmente el intercambio franco entre las culturas de la humanidad; por ejemplo, los factores económicos, políticos y militares, entre otros. Asimismo, cabe destacar dos
} 
este análisis, cabe destacar que este proyecto exige no caer en la ideología del diálogo descontextualizado que no toma en cuenta las asimetrías del poder que reinan en el mundo (Fornet-Betancourt, 1999; Tubino, 2004). Para ello, inscribe la afirmación de la diversidad cultural en un proyecto de "diálogo intercultural" que es "proyecto alternativo de comunicación e intercambio entre culturas como horizontes complejos y ambivalentes, cargados de contradicciones y conflictos" (Fornet Betancourt, 1999). En este sentido, uno de sus ejes programáticos apunta a reordenar los principios de la ciencia, lo que implica reformular los principios reduccionistas de la ciencia positivizada o ciencia moderna y su lógica científico-técnica. Ello significa, a su vez, buscar una episteme que supere el dualismo sujeto-objeto, la visión mecánica de la naturaleza, el humanismo antropocéntrico, el progresismo y, principalmente para el caso que nos ocupa, el principio de independencia cultural o descontextualización de la ciencia y el de su despersonalización y descorporalización (Fornet-Betancourt, 2009); lo que en concreto significa que los investigadores y sus colaboradores en ese proceso aparecen como seres sin biografia y sin cuerpo.

Sobre este contexto buscamos perfilar el carácter intercultural y crítico de la propuesta tayloriana. Para ello, en la primera parte de esta nota nos referimos a la concepción expresivo-constitutiva del habla humana como trasfondo que permite comprender el carácter hermenéutico e intercontextual del lenguaje "científico" que el filósofo canadiense propone; para luego avanzar hacia la comprensión del papel que juega dicho lenguaje en la superación del etnocentrismo en las ciencias. En una segunda parte, vinculamos la idea de un lenguaje de contrastes sutiles con las dimensiones epistemológicas, éticas y estéticas que estarían presentes cuando Taylor (2005) hace referencia al carácter experiencial de las significaciones y cuando retorna a la tradición romántica para hablar de la palabra concreta viviente. Finalmente, concluimos que para comprender la diversidad cultural, las ciencias humanas y sociales necesitan de la articulación de unos lenguajes-vivos, que respeten la condición de agente corpóreo, dialógico y temporal a partir de la cual el ser humano habita lo interhumano.

\section{CONCEPCIÓN EXPRESIVO-CONSTITUTIVA DEL LENGUAJE HUMANO.}

Para comprender la propuesta de un "lenguaje de contrastes sutiles" resulta clave la distinción que Taylor (2005) realiza entre la concepción instrumental-designativa del lenguaje y la concepción expresivo-constitutiva del habla humana; las cuales devienen en dos modos opuestos de percibir y construir el mundo. Por una parte, la concepción instrumental-designativa hace una separación entre pensamiento y lenguaje; transforman-

principios de la interculturalidad crítica que pueden servir como trasfondo para repensar el carácter epistémico y metodológico de nuestras investigaciones sociales: 1) "Recuperar la memoria de los excluidos" y 2) "Visibilizar los conflictos interculturales del presente como expresión de una violencia estructural más profunda, gestada a lo largo de una historia de desencuentros y postergaciones injustas" (Tubino, 156-157). Ambos principios permitirían hacer frente a las causas contextuales de la inoperancia del diálogo actual. 
do a este último en un mero instrumento que solo permite nombrar las cosas del mundo o designar lo previamente pensado. Por otra parte, la concepción expresivo-constitutiva no admite dicha separación porque considera que el lenguaje es "pensamiento/discurso" que aparece como una articulación creativa que constituye nuestro mundo y a nosotros mismos como seres-en-el-mundo.

A partir del contraste entre estas dos concepciones del lenguaje, Taylor (2005) desarrolla una reflexión que nos permite comprender que en nuestra tradición occidental nos han educado para pensar que el lenguaje solo es un vehículo o instrumento del pensamiento; que resulta muy peligroso, pues distorsiona la realidad y, en consecuencia, debemos elegir de manera escrupulosa y lo más "objetivamente" posible las palabras que usamos para designar las cosas "tal y como son". Según Taylor (2005) esta es la postura que alimenta al objetivismo de las ciencias humanas, que nos ha llevado a una obsesión por las definiciones, las categorías o las clasificaciones; para, luego, fijarlas de un modo esencialista en nuestras prácticas. Asimismo, se nos ha educado para pensar que el lenguaje expresivo es propio del arte, por ejemplo, de la literatura y como tal sería un lenguaje más libre que puede permitirse "ciertas confusiones"; ya que se supone nos hablaría de "ficciones" y no de realidades "objetivas". En otras palabras, se nos ha enseñado a percibir que el lenguaje humano es esencialmente designativo y que su carácter expresivo es solo una función secundaria. Sin embargo, Taylor (2005) nos permite entender que la expresividad es el ethos del lenguaje humano y no solo una función. Nos señala que el lenguaje humano es expresivo; pero, también, que esta expresividad es constitutiva y constituyente. Al respecto, señala: "El lenguaje hace posible una entera gama de sentimientos, de actividades y de relaciones esencialmente humanos; deshace el marco de las formas de vida prelingüísticas (...) concede un papel creativo a la expresión". (Taylor, Argumentos, 150)

En breve cabe señal que la concepción expresivo-constitutiva del lenguaje proviene del mundo germano y habría sido formulada originalmente en 1772 por Herder en su "Ensayo sobre el origen del lenguaje", para ser después retomada por la hermenéutica heideggeriana-gadameriana. El ensayo de Herder es elaborado como una alternativa al planteamiento que en 1746 desarrolla Condillac en el "Ensayo sobre el origen de los conocimientos". La perspectiva Herderiana concibe el lenguaje como aquello que hace posible nuevas intenciones o propósitos, nuevos significados, nuevas conductas $\mathrm{y}$, en consecuencia, no es explicable en el marco de una vida humana sin lenguaje (Taylor, 1997). Desde esta teoría, en cada acto de habla está inscrita la posibilidad de crear/expresar/articular explicaciones, emociones y diálogos; es decir, crear un mundo (humano) o abrir (nos a) un mundo nuevo. Así, la expresión lingüística adquiere un carácter creativo o configurador: no se limita a apuntar hacia algo que ya estaba allí, sino que abre nuevas posibilidades y relaciones; introduce nuevos significados y valoraciones. Es decir, el lenguaje está dotado de una capacidad creativa propia que permite transformar el caos de las sensaciones en imágenes. Esta capacidad creativa primigenia es la fuerza poética que genera metáforas por medio de las cuales lo real comienza a ser comprensible. Así, la apertura al mundo se inicia "con el lenguaje 
natural o materno que descansa no en la razón abstracta y calculadora, sino en la imaginación poética" (Garagalza, 356).

Siguiendo a Taylor (2005), podemos comprender que la separación entre pensamiento y lenguaje es un reduccionismo que empobrece y deshumaniza a las ciencias humanas, pues conlleva a la mera designación de los "hechos", lo que termina por instrumentalizar y fragmentar las relaciones que establece el ser humano; ya sea con otros seres humanos, con la naturaleza o consigo mismo. En este sentido, para Taylor (2005) es central realzar la concepción expresivo-constitutiva del lenguaje en las ciencias humanas, pues esta concepción nos permite comprender que hablar sobre las cosas y redefinirlas (función designativa del lenguaje) solo es posible desde una configuración emotivovalorativa (función expresiva del lenguaje) y desde las interacciones humanas (función pragmática del lenguaje). De este modo, para Taylor (2005) la concepción expresivoconstitutiva es la condición de posibilidad para que las ciencias humanas puedan desarrollar un lenguaje y un mundo holista; es decir, un lenguaje/mundo capaz de hacer frente al atomismo social, a la fragmentación de la existencia humana, a la instrumentalización del espacio vital y a la pérdida de libertad política.

EL LENGUAJE EXPRESIVO-CONSTITUTIVO COMO MEDIO PARA SUPERAR EL ETNOCENTRISMO DE LAS CIENCIAS HUMANAS INTERPRETATIVAS.

La concepción expresivo-constitutiva del lenguaje le permite a Taylor (2005) asumir el problema del habla humana como un asunto de significación y, a su vez, estudiar la falta de comprensión de una cultura diferente como la ausencia de significaciones compartidas. Aquí, el desafío de comprender a los otros remite necesariamente a la autocomprensión propia y ajena $\mathrm{y}$, por lo tanto, constituye un problema intersubjetivo e intercontextual; complejidad que las ciencias humanas solo pueden resolver mediante un lenguaje que permita comparar de manera no distorsionante las significaciones propias y ajenas que entran en juego en un contexto espacio-temporal determinado. Es decir, las ciencias humanas necesitan un lenguaje que permita expresar el contraste cualitativo o, en otros términos, articular comparaciones no jerarquizables de las significaciones que - en principio - resultan incomprensibles en el lenguaje de la autocomprensión del propio investigador. En este sentido, Taylor redescribe el concepto de significación (significado, sentido, valor) en términos de "significación experiencial" (Taylor, La libertad, 153, 159) para realzar que:

1) La significación es para un sujeto: no es la significación de la situación in vacuo, [...] 2) es significación de algo; o sea, podemos distinguir entre un elemento dado — situación, acción o lo que fuere-y su significación. [...] 3) Las cosas solo tienen significación en un campo, esto es, en relación con las significaciones de otras cosas (152). 
Este concepto alude a un campo de significación que actúa como trasfondo (Taylor, 2005), en donde el comprender mismo resulta una acción (social) gobernada por significaciones intersubjetivas: La significación siempre "es significación de algo para un sujeto, en un campo" (Taylor, La libertad, 153). Aquí, la "definición de la situación" que cada actor se ve obligado a elaborar para poder actuar (Schuzt, 2003)2, deviene en una experiencia-vivida que lo transforma en actor autointerpretante. Es decir, un ser-actuante-en-el-mundo, cuya "identidad corpórea, temporal y dialógica" (Taylor, La ética, 131-132) le permite resignificarse constantemente, al resignificar su mundo y el de los otros. Esta autodefinición o autointerpretación que el otro hace de sí mismo, mediante una definición de su propia situación biográfica, es el punto de partida de toda comprensión auténtica del otro que, finalmente, llevaría a ampliar nuestra propia autocomprensión. Así, tanto el primado de la definición de la situación como la capacidad de agencia autointerpretante del ser humano nos remiten al postulado éticoepistémico de que el investigador debe describir las acciones sociales del otro como elecciones que ese otro desarrolla activamente y que ocurren siempre dentro de un campo de posibilidades problemáticas. Ello significa que el otro vive en un escenario que no es definido por mí, que lo que es significativo para el otro no coincide con lo que es significativo para mí; sin embargo, ello no lo convierte en un utensilio mío. El otro sigue activamente definiendo su situación y yo solo lo puedo comprender como no siendo yo, pues sus actividades y proyectos no son las mías y están más allá de mis posibilidades aceptadas (Shütz, 2003). En este sentido, la hermenéutica tayloriana nos dice que "la explicación de las significaciones" (comprensión) solo podemos alcanzarla "situando el idioma en la matriz de nuestras preocupaciones, prácticas y actividades, en suma, relacionándolo con nuestra forma de vida" (Taylor, Hegel, 307-308). De este modo, las matrices de preocupaciones propias y ajenas actúan como un trasfondo (algo no articulable) que permanece-posibilitando la articulación de marcos narrativos en los cuales podemos contrastar la definición de la situación que realiza cada actor.

En esta lógica, el conocimiento adquiere un carácter esencialmente comparativo y, por lo tanto, la comparación deja de ser un elemento accesorio en las ciencias humanas y pasa a ser decisiva para ampliar la comprensión. Aquí el concepto de comparación se entiende como contraste-cualitativo, expresión-genuina o articulación desde un trasfondo que como tal permanece inarticulable. La comparación no conlleva la lógica de la jerarquización o categorización, pues aquí ella no opera según los

\footnotetext{
2 Tomamos este concepto de "definición de la situación" desde la sociofenomenología de Alfred Schütz, quien plantea que en cualquier momento de su vida diaria, el hombre se encuentra en una situación biográfica determinada, vale decir, en un medio físico y sociocultural que él define y dentro del cual ocupa una posición, no solo en términos de espacio físico y tiempo exterior, o de su estatus y su rol dentro del sistema social, sino también una posición moral e ideológica. Decir que esta definición de la situación está biográficamente determinada equivale a decir que tiene su historia; es la sedimentación de todas las experiencias previas del hombre, organizada en el patrimonio corriente de su acervo de conocimiento a mano, y, como tal es su posesión efectiva, dada a él y solo a él (40).
} 
parámetros de un lenguaje previamente definido (lógica instrumental-designativa), sino que remite al carácter simbólico e interpretativo de todo lenguaje y conocimiento. En este sentido, Taylor (2005) nos advierte respecto de la sobreutilización del concepto de interpretación. Interpretar — nos señala - no es simplemente aplicar un repertorio de lenguajes en una sociedad o cultura determinada; lo que, en otras palabras, sería la aplicación etnocentrista de "mi lenguaje" o la simple traducción literal descontextualizada. Más exactamente, la interpretación sería un proceso que tiene relación con la capacidad de situarnos en un contexto específico y desde allí establecer comparaciones de repertorios culturales (lenguajes) en términos de diferencias no jerarquizables; es decir, en términos de perspectivas distintas de "algo" (por ejemplo, de una institución, una acción, una emoción, una actitud) que percibimos como similar en distintas sociedades o culturas ${ }^{3}$.

$\mathrm{Al}$ respecto, Taylor (2005) nos recuerda que los conceptos cardinales en ciencias humanas son conceptos de diferencias entre sociedades, entre formas de vida; a los que solo se puede acceder desde los márgenes o desde el exterior de cada una de ellas. Para aprehender esta dimensión comparativa, Taylor sugiere que las epistemologías de las ciencias sociales contemporáneas podrían reorientar el trabajo de configuración de nuevos conceptos, según la siguiente afirmación: "lejos de que ciertos criterios dirijan la comparación, esta suministrará el criterio o la idea formadora (...) No tengo la idea: la aporta la comparación" (Dumont citado por Taylor, La libertad, 22). Desde este punto de vista, las ciencias humanas se transforman en unas prácticas culturales autodefinitorias (Taylor, 2005) que deben pensar sus propias condiciones: aquello que hace que sus explicaciones sean efectivamente esclarecedoras, teniendo presente que esas condiciones varían según los dominios científicos y culturales. De este modo, Taylor (2005) está planteando una crítica al universalismo y al objetivismo de las ciencias por la vía del reconocimiento del carácter holista, dialógico y situado del lenguaje humano. Asumir la perspectiva de un lenguaje humano expresivo-constitutivo de los modos de ser, de sentir, de actuar y de convivir de los distintos grupos socioculturales, significa aceptar que ya no habría una respuesta única a las indagaciones, sino que variadas respuestas según la diversidad de las ciencias y de las culturas.

\footnotetext{
${ }^{3}$ En este sentido, la propuesta tayloriana de un lenguaje de contrastes sutiles sintoniza con la propuesta de Boaventura de Sousa Santos $(2009,2011)$ referida a la traducción intercultural como principio orientador de la ecología de saberes que estaría a la base de las epistemologías del sur. La traducción intercultural, propuesta por el pensador portugués, nos habla de crear inteligibilidad recíproca entre las experiencias del mundo, tanto las disponibles como las posibles. Se trata de una traducción entre saberes que incide sobre las prácticas y sus agentes, dando lugar a una hermenéutica diatópica que consiste en un trabajo de interpretación entre dos o más culturas con el objetivo de identificar preocupaciones similares entre ellas y las diferentes respuestas que proporcionan. Así se puede realizar una traducción, por ejemplo, entre diferentes concepciones de la vida productiva, entre varias concepciones de sabiduría o diferentes cosmovisiones.
} 


\section{CONTRASTE SUTIL ENTRE SIGNIFICACIONES-EXPERIENCIALES}

El sentido hermenéutico de las ciencias humanas en el pensamiento de Charles Taylor está orientado a desarrollar un lenguaje que permita comparar de manera no distorsionante los procesos de asignar significado, sentido y valor a una acción por parte de un agente en una situación dada. De este modo, señala:

...cuando queremos entender otra sociedad de manera adecuada, no debemos adoptar nuestro lenguaje de la comprensión ni el de ella, sino más bien lo que podríamos llamar un lenguaje de contrastes transparentes [sutiles o perspicaz]. Me refiero a un lenguaje en el cual podamos formular ambos modos de vida en cuanto posibilidades alternativas, vinculadas a ciertas constantes de lo humano vigentes en uno y otro (La libertad, 211. El destacado es nuestro).

En este sentido, "un lenguaje de contrastes sutiles" sería un medio lingüístico capaz de revelar los contrastes de "significaciones experienciales" (Taylor, La libertad, $153,159)$ entre diferentes culturas. Se trataría, de una manera de interpretar y de usar el lenguaje humano que permitiría construir un lenguaje nuevo: Un lenguaje que no es tú lenguaje, ni mi lenguaje; sino nuestro lenguaje. Así, esta propuesta no consiste en crear un lenguaje independiente de los hablantes, cuyo desarrollo conlleve pretensiones universalistas abstractas. Tampoco consiste en el lenguaje de un "yo" o el lenguaje de un "tú". Por el contrario, se trata de un lenguaje concreto que se construye, continuamente, a partir de un "nosotros". Se trataría de un lenguaje vivo que, para ser tal, requiere de la participación intersubjetiva e intercorpórea de los hablantes en un espacio social común.

La propuesta de un "lenguaje de contrastes sutiles" superaría tanto el etnocentrismo como el relativismo, porque consistiría en una especie de tercer lenguaje, que no es ni el lenguaje del sujeto-observador, ni el lenguaje del sujeto-observado; sino un lenguaje en el cual cada una de las partes implicadas pueda reformular su propio modo de vida y el del otro como posibilidades alternativas de lo humano. Aquí, el lenguaje adopta la forma de un ejercicio constante de comparación, contraste y transformación de lo propio en presencia de lo otro (de otra comunidad dialógica y cultural); lo que se logra con una dinámica heurística de invención de nuevos lenguajes de interpretación que opera mediante la creación de nexos significativos entre dos planos no conectados antes (Lazo Briones). En este sentido, esta propuesta conlleva la idea de que los conceptos generales no se dan en el método científico ni en los hechos en bruto; con lo que quedan superados tanto los conceptos explicativos considerados neutrales (universalismo cientificista dogmático), como la dependencia respecto de los conceptos autóctonos (que dan lugar al relativismo y a un comunitarismo cerrado sobre sí mismo). Charles Taylor lo plantea del siguiente modo:

Ese lenguaje de contrastes podría mostrar que el lenguaje de la comprensión de la otra sociedad está distorsionado o es inadecuado en algunos aspectos, o emitir un juicio similar sobre el nuestro (en cuyo caso tal vez consideraríamos que 
entenderlos provoca una alteración de nuestra autocomprensión $\mathrm{y}$, por consiguiente, de nuestra forma de vida, un proceso del que la historia conoce muchos ejemplos. También podría mostrar que ambos se encuentran en esas condiciones (Taylor, La libertad, 211-212).

Así, Taylor (2005) dibuja la alternativa de un lenguaje por medio del cual las sociedades, culturas o instituciones comparadas se puedan describir como dos o más posibilidades distintas de realización de una antropología común; en el sentido de ser una antropología compartida que se abre a la alteridad, porque asume la existencia de algunas invariantes de la condición humana, como lo es la capacidad expresivoconstitutiva, entre otras. Sobre este contexto, comprender es describir una práctica o una institución como una posibilidad en el marco de otras posibilidades. Al respecto, cabe señalar que esta propuesta tiene un trasfondo epistemológico-ético, pues conlleva la tarea de abrir las ciencias humanas a otras "formas de vida" reconociéndolas como un aporte para superar el atomismo social vigente en nuestra sociedad occidental.

La noción de un "lenguaje de contrastes sutiles" es planteada por Taylor como una tarea vigente para los investigadores en estudios culturales, cuyo desarrollo consistiría en identificar específicamente cómo podría operar este "uso del lenguaje" de carácter no etnocentrista. Pensamos que se trata de una tarea compleja que exige, necesariamente, una lucha continua por el reconocimiento mutuo de los actos de habla; pero a partir de una lucha, también continua, con nuestras propias formas habituales de pensar, de sentir, de decir y de actuar. El desarrollo de "un lenguaje de contrastes sutiles" implica expresar y contrastar todo aquello que los interlocutores dejan implícito cuando usan un lenguaje instrumental-designativo; exige, por tanto, dialogar acerca de los sentidos, expresando las emociones y los valores que configuran las prácticas cotidianas más autodefinitorias de cada participante. En este sentido, pensamos que el contraste de sutilezas requiere de una "palabra concreta viviente" que permita reconectarnos con la vida, aspecto que desarrollamos a continuación.

\section{RESCATANDO LA PALABRA CONCRETA VIVIENTE}

En la búsqueda de expresiones sutiles que permitan el desarrollo de sensibilidades interculturales éticamente articuladas, Taylor nos habla de la capacidad expresivo-constitutiva del lenguaje humano que, gracias a su fundamental carácter holista y dialógico, nos sitúa como seres capaces de dar significación ética a nuestros actos. Situados en esta dimensión, establecemos nuestra actitud y posición frente a las cosas, de modo que la diversidad de las formas simbólicas se transforma en diversidad de posibilidades expresivas humanas (Lazo Briones). En otras palabras, la expresividadconstitutiva de todas nuestras acciones implica, necesariamente, adoptar un primigenio punto de vista hermenéutico-ético que Taylor rescata bajo la forma de una orientación prudencial de la razón práctica (Lazo Briones); orientación que las actuales ciencias humanas interpretativas necesitan reconsiderar para superar el etnocentrismo. 
En este sentido, Taylor se remonta a la tradición romántica y destaca la idea de reflexión propuesta por Herder que, al estar en el núcleo del lenguaje humano expresivo-constitutivo, aparece como acción creativa o articulación expresiva que permite tomar distancia o abrir un espacio respecto del inmediato e instintivo significado de las cosas. Con ello, el lenguaje expresivo permite no solo la claridad de quienes somos, sino también lo que podemos y tenemos que ser como humanos (Lazo Briones). Así, mediante el lenguaje, el juego esencial de autointerpretación de la identidad humana se da en el entrecruzamiento de hermenéutica y ética; a partir de lo cual se hace evidente que el "yo expresivo" o la capacidad humana de autointerpretar su propio ser, es también un asunto que tiene dimensiones morales: "cada acto evaluador hecho en el seno del lenguaje es al mismo tiempo un acto de interpretación de sus sentidos posibles para la propia condición de ser" (Lazo Briones, 210).

Sobre este contexto, la posibilidad de un lenguaje de contrastes sutiles habla de la necesidad de un lenguaje que nos permita superar el atomismo social y la fragmentación humana. Es decir, un lenguaje capaz de oponerse al yo escindido y atormentado que ya, en su tiempo, destacaba la tradición romántica y que Taylor rescata a partir de los aportes de Herder, Humboldt y Hamman. Lo que subraya Taylor, para superar el etnocentrismo de las ciencias humanas contemporáneas, es que no se debe confundir la capacidad expresivo-constitutiva humana con un autoexpresivismo egocéntrico e individualista centrado en una razón desvinculada. Al respecto, el aporte de Herder es central porque permite ver que la comprensión no se logra por medio del uso de palabras desvinculadas, sino que mediante su significación que solo se alcanza dentro de un contexto de uso de un lenguaje; pues, en último término, las palabras están incrustadas en un modo de vida.

De este modo, la capacidad de comprender de modo no etnocentrista un fenómeno por parte de un investigador, dependerá de su capacidad lingüística de situarse en las prácticas sociales que constituyen el lenguaje de los otros. Esta capacidad implica la interpretación de ciertas valoraciones claves para la vida de una cultura (sus valoraciones fuertes) que difícilmente pueden ser comprendidas desde una posición teorética. En este sentido, los investigadores necesitan desarrollar el punto de vista expresivo-reflexivo que - al recuperar el trasfondo y situar el pensamiento- permite reorientar las prácticas científicas e investigativas en una perspectiva hermenéutico-ética; punto de vista mediante el que el acto expresivo es simultáneamente acto de interpretación y de evaluación (Lazo Briones). Entendida así, en el campo de las ciencias humanas y sociales, la acción expresiva aparece, necesariamente, como la acción interpretativa ' $y$ ' emotivo-valorativa, mediante la cual los investigadores y los sujetos colaboradores de la investigación articulan y actualizan su postura frente al mundo.

En el marco de estos planteamientos ético-epistemológicos incluimos la dimensión estética, por medio de la noción palabra concreta viviente que Taylor (2006) rescata desde la crítica de la racionalidad desvinculada que desarrolló el romanticismo; y que nosotros vemos muy relacionada con la propuesta de un lenguaje de contrastes sutiles. La palabra concreta viviente es un enunciado que busca superar la racionalidad mecanicista 
que se retroalimenta por medio de una "prosa corriente" que al operar con un lenguaje de opuestos muertos desplaza la atención de las cosas en sí mismas a lo que hacemos mediante ellas. En su tiempo, los expresivistas románticos denunciaron y combatieron la "prosa corriente", porque amarra a categorías mecanicista-utilitaristas que llevan a manejar el mundo de manera convencional. Siguiendo a Taylor, para superar esta visión mecanicista podemos acudir a la poesía que restituye el contacto vital con la realidad y restaura nuestra visión de las cosas por medio de un lenguaje fresco e intuitivo: "En la prosa [corriente] «utilizamos las palabras divorciadas de toda visión de lo real». La poesía está destinada a penetrar por medio de esa abstracción. «Está siempre presta a detenerse y obligarte a mirar fijamente algo físico para con ello prevenir que te deslices por un proceso abstracto»"' (Taylor, Las fuentes, 625).

La palabra concreta viviente aún nos habla de la necesidad humana permanente de lograr superar la sujeción del yo a categorías desvinculantes, que llevan al olvido del ser de las cosas que ha quedado oscurecido por la cosmovisión moderna. El ser humano todavía busca desplazarse desde un yo puntual y desvinculado hacia el fluir de la experiencia, hacia nuevas formas de unidad, hacia el lenguaje en su variedad de formas (Taylor, 2006). Así, el ser humano tiene la necesidad de deslizarse hacia lenguajes más sutiles, tiene el deseo de nuevas palabras que permitan fluir hacia experiencias más profundas que abran a otra dimensión de la vida. En este sentido, podemos reconsiderar el carácter expresivo-constitutivo que Herder subraya para el habla, no solo en el sentido de que el lenguaje humano permite expresar un nuevo tipo de conciencia reflexiva más refinada; sino, también, nuevos modos de sentir. Al expresar nuestros sentimientos, ellos adquieren una dimensión reflexiva que los transforma: "El animal con lenguaje puede sentir no solo ira, sino también indignación, no solo amor sino admiración" (Taylor, 1997).

Si el lenguaje sirve para expresar/realizar maneras de sentir, es decir, para crear nuevos sentimientos sin identificarlos con descripciones previas (porque de lo contrario serían sentimientos ya existentes); entonces el lenguaje no puede reducirse a la actividad de hablar sobre las cosas. Este aspecto del lenguaje es importante para las ciencias humanas contemporáneas, ya que la práctica de investigar lo humano desde una perspectiva expresivo-constitutiva, no puede basarse en descripciones sobre las cosas que supuestamente estarían separadas de las emociones que las constituyen. Al respecto, Taylor (1997) nos señala que no podemos marcar una frontera alrededor del lenguaje de la prosa descriptiva, separándolo de otras creaciones humanas simbólicoexpresivas: poesía, música, pintura, danza; debido a que hablar acerca de algo es solo uno de los campos de la naturaleza constitutiva del habla; otro campo son las emociones humanas, muchas de las cuales no se transmiten mediante palabras.

Pensamos que la palabra concreta viviente es un concepto evocador vigente que nos permite repensar, o pensar de otra manera, las fuentes emotivo-valorativas que articulan las identidades y alteridades cuando estas entran en las dinámicas de reconocimiento mutuo. Especialmente, para el caso que nos ocupa -el reconocimiento mutuo o contraste sutil de significaciones entre el mundo de la ciencia y la vida de las 
culturas - este concepto evocador remite al acto poético y narrativo que alejaría al investigador de una óptica neutral; situándolo, más bien, en el camino de la memoria narrativa. Esta busca articular "algo que está más allá del yo", "algo más que una reacción subjetiva" (Taylor, La ética, 115, 118); algo para lo cual se carece de las palabras adecuadas, pues se trata de algo que está más allá del 'yo' y del 'tú' y que requiere para su expresión/creación de una comunidad dialógica situada en un tiempo y un espacio concretos.

Asimismo, la actualidad del concepto palabra concreta viviente puede ser apreciada de mejor manera si relacionamos dicho enunciado romántico con la distinción que realiza Merleau-Ponty entre palabra hablante y palabra hablada, en su libro Fenomenología de la percepción. La distinción entre estos dos conceptos permite percibir el contraste entre un discurso auténtico - palabra hablante - y un discurso sobre discursos que da cuenta de expresiones ya acontecidas - palabra hablada-. Entre ambos discursos habría un mutuo condicionamiento que posibilita otros actos de expresión auténtica, como los de un escritor, un artista o un filósofo. A partir de esta distinción: "La comunicación lingüística es, por un lado, una comunicación intelectual cuando la palabra se apoya en un concepto previo, sin dejar nunca de ser, por otro lado, una comunicación vital e incluso corporal, cuando la palabra no traduce un pensamiento ya hecho, sino que contribuye a formarlo" (Paredes, 55). A su vez, retomando la perspectiva hermenéutica, podemos relacionar dicho concepto con el poder redescriptivo de la metáfora viva, que Ricoeur (2001) define como la actividad metafórica primigenia que transforma la realidad al expandir los límites de lo previamente definido. Palabra concreta viviente, palabra hablante y metáfora viva conforman una trilogía que, desde tradiciones filosóficas distintas, nos sugiere la necesidad de escuchar la oralidad y las voces silenciadas por una ciencia occidental moderna y su lógica científico-técnica. Justamente, lo que le falta al científico social occidental y moderno es conectarse con las voces de la memoria narrativa propia y ajena; ámbito que cotidianamente es habitado por las culturas y pueblos originarios que permanecen excluidos del mundo científico.

\section{CONCLUSIÓN}

La antropología hermenéutica de Charles Taylor entiende al ser humano como ser de significados, animal de lenguaje o agente autointerpretante. Al respecto, nos señala que "somos agentes corpóreos", que vivimos "en condiciones dialógicas" y que habitamos "el tiempo de un modo especialmente humano", es decir, "dando sentido a nuestras vidas en la forma de una historia que conecta el pasado del que procedemos con nuestros futuros proyectos" (Taylor, La ética, 131-132). De esta condición humana corpórea, dialógica y temporal deriva la exigencia de unas ciencias humanas y sociales que respeten al ser humano como ser libre-situado.

En este sentido, las ciencias humanas contemporáneas necesitan una palabra concreta viviente que vaya nutriendo la posibilidad de un lenguaje de contrastes sutiles; 
es decir, un lenguaje que - confrontando las sutilezas de los distintos modos de vida que entran en contacto - nos vaya permitiendo crear nuevos y más refinados modos de ser, de sentir, de actuar y de convivir con nosotros mismos, con los otros, con la naturaleza y con lo trascendente. Si asumimos la palabra concreta viviente como una expresión que - lejos de remitirnos a un subjetivismo con sesgos egocéntricoinstrumentales - más bien nos orienta hacia un renovado sentido de pertenencia, "un sentido más fuerte, más interior de vínculo" (Taylor, La ética, 120); entonces este concepto evocador puede ayudarnos a rearticular el mundo de la investigación social como una creación que necesariamente coconstruimos con los otros mediante el lenguaje. En otras palabras, podemos acoger la palabra concreta viviente como ámbito expresivo y constitutivo desde el cual podemos configurar un lenguaje de contrastes sutiles entre mundo científico y vida de las culturas, porque en dicho ámbito habitamos de otro modo el tiempo y el espacio existenciales. Por esta vía, la propuesta de un lenguaje de contrastes sutiles es incompatible con una epistemologia intercultural funcional porque nos dispone a habitar el tiempo y el espacio de las investigaciones sociales como lugares y prácticas de abundancia irreductible — siempre ricos y diversos en su complejidad - y no como simples espacios de carencia o precariedad. La mirada reducida y reduccionista, desde la cual hoy se usa el espacio vital de la investigación social, necesita del contraste sutil entre las palabras sentidas y vividas, que proviniendo de lugares distintos, ayuden a contextualizar las ciencias y a reconocer lo humano que habita en ellas.

\author{
Universidad Católica de Temuco* \\ Manuel Montt $N^{\circ}$ 056, Temuco (Chile) \\ scarcamo@uct.cl
}

\title{
OBRAS CITADAS
}

Beuchot, Mauricio. Tratado de hermenéutica analógica: Hacia un nuevo modelo de interpretación. México D.F: Facultad de Filosofía y Letras UNAM, Editorial Itaca, 2009.

De Sousa Santos Boaventura. "Epistemologías del Sur". Utopía y Praxis Latinoamericana. Revista Internacional de Filosofia Iberoamericana y Teoría Social 54 (2011):17-39.

__ Una epistemología del sur: la reinvención del conocimiento y la emancipación social. México: Siglo XXI-CLACSO, 2003.

Fornet-Betancourt, Raúl. 'Una meditación de la ciencia”. Utopía y Praxis Latinoamericana. Revista Internacional de Filosofia Iberoamericana y Teoría Social. MaracaiboVenezuela: CESA-FACES-Universidad del Zulia, 2009: 127-134

__ "Supuestos filosóficos del diálogo intercultural" en Revista de Filosofia, Vol. 32 No 96. Ciudad de México: Universidad Iberoamericana, 1999. Disponible en: http://www.ensayistas.org/critica/teoria/fornet 
Garagalza, Luis. "Lenguaje y humanismo". En Claves de hermenéutica para la filosofia, la cultura y la sociedad. Ortiz-Osés, A. y Lanceros, P. (Comp.). Bilbao: Universidad de Deusto, 2005: 352-361.

Lazo Briones, Pablo. Interpretación y acción. El sentido hermenéutico del pensamiento ético-político de Charles Taylor. México: Ediciones Coyoacán, 2007.

Merleau-Ponty, Maurice. Fenomenología de la percepción. Barcelona: Ediciones Península, 1975.

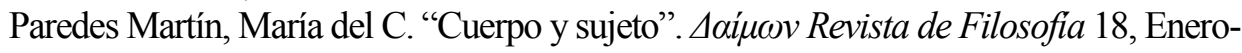
Junio (1999).

Ricoeur, Paul. La metáfora viva. Madrid: Editorial Trotta, 2001.

Schutz, Alfred. El problema de la realidad social. Buenos Aires: Amorrortu, 2003.

Taylor, Charles. Las fuentes del yo: la construcción de la identidad moderna. Barcelona: Paidós, 2006.

_ La libertad de los modernos. Buenos Aires: Amorrortu, 2005.

—_ Argumentos filosóficos. Ensayos sobre el conocimiento, el lenguaje y la modernidad. Barcelona: Paidós, 1997.

— L L ética de la autenticidad. Barcelona: Paidós, 1994. Hegel y la Sociedad moderna. México: FCE, 1983.

Tubino, Fidel. "Del interculturalismo funcional al interculturalismo crítico". Rostros y fronteras de la identidad. Samaniego, M. y Garbarini, C. G. (Comps.) Temuco: Universidad Católica de Temuco, 2004:151-164. 